COMMENT

https://doi.org/10.1038/s41467-020-18052-0

\title{
Unfinished business after five decades of ozone-layer science and policy
}

\author{
Susan Solomon (iD) ${ }^{1 凶}$, Joseph Alcamo $^{2} \&$ A. R. Ravishankara (iD ${ }^{3}$
}

The Montreal Protocol has begun to heal the Antarctic ozone hole and avoided more global warming than any other treaty. Still, recent research shows that new unexpected emissions of several chlorofluorocarbons, carbon tetrachloride, and hydrofluorocarbons, are undermining the Protocol's success. It is time for policymakers to plug the holes in the ozone hole treaty.

The Montreal Protocol is a landmark example of policy and science teaming up to deal with a threat of global proportions. In the 1970s, the scientific community foresaw the threat posed by anthropogenic emissions to the ozone layer that protects life on Earth from harmful ultraviolet radiation. By the mid-1980s, this threat proved far worse than forecast, with a massive and unexpected springtime Antarctic ozone 'hole' forming due to the emissions of ozone-depleting substances (ODS), especially chlorofluorocarbons (CFCs). These scientific findings, together with clamour from civil society and governments, led to action. Negotiations under the umbrella of United Nations Environment Programme produced a political declaration in 1985, 'The Vienna Convention', followed in 1987 by an international agreement to act, the 'Montreal Protocoll'.

The Protocol has accomplished a lot. By 2009, governments had phased out the consumption of $98 \%$ of the chemicals they agreed to in the Protocol; abundances of ODSs in the atmosphere are decreasing according to recent observations and more than 250 millions of cases of skin cancer and almost 50 millions of cases of cataracts will have been averted by the end of the century ${ }^{1}$. As early as 1987 , the Parties emphasized that they were 'Conscious of the potential climatic effects of emissions of these substances' (https://reaties.un.org/doc/publication/unts/ volume\%201522/volume-1522-i-26369-english.pdf). Indeed, as a bonus, by 2010 the phaseout of these climate-threatening gases avoided about 15 gigatonnes $(\mathrm{Gt})$ of equivalent $\mathrm{CO}_{2}$ emission per year, much more than the $2 \mathrm{Gt}$ per year that were targeted by the Kyoto Protocol ${ }^{2}$.

\section{Much done, but much unfinished}

Why has the ozone treaty been so successful? Some say it was the manageable number of sources of ODSs, whereas others highlight the actions of industry to produce practicable and profitable alternatives to ODSs. Financial assistance from OECD nations may have also encouraged all countries to participate in the treaty ${ }^{1}$. A keystone to the Protocol's success has been its flexibility and the openness of the Parties to adapt to changing political climates and new knowledge provided by the Protocol's technical panels ${ }^{1}$. This has led to revisions that have elevated the

\footnotetext{
${ }^{1}$ Department of Earth, Atmospheric, and Planetary Sciences, Massachusetts Institute of Technology, Cambridge, MA 02139, USA. ${ }^{2}$ Sussex Sustainability Research Programme, School of Global Studies, University of Sussex, Falmer BN1 9SL, UK. ${ }^{3}$ Departments of Chemistry and Atmospheric Science, Colorado State University, Fort Collins, CO 80523, USA.『email: solos@MIT.EDU
} 
original aim of small reductions in CFC production to one of total global phaseout of production and consumption of these chemicals ${ }^{3}$.

Re-appearing CFCs and HFCs. Even though extensive reductions in global ODS production have been achieved, the impact of remaining emissions loom large. Many of the remaining gases are long-lived in the atmosphere, which means that they will continue to build up even if emissions are small. In addition, disturbing evidence has emerged since the mid-2010s that the treaty is not working as well as expected. CFC-11 emissions increased by about $30 \%\left(15 \pm 5 \mathrm{Gg} /\right.$ year or about $0.8 \mathrm{Gt} \mathrm{CO}_{2}$-eq/decade) from the early- to mid-2010s (Fig. 1a) ${ }^{4}$, which is not explainable unless there is new production in violation of the Protocol ${ }^{5}$. The quick detection of this problem is an important scientific success-so far, the added CFC-11 has not been enough to significantly delay the closing of the ozone hole, but continuing additions beyond 2030 would impede successful healing of the ozone layer by a decade or more ${ }^{6,7}$. All is not well with the other CFCs either. For example, concentrations and inferred emissions of CFC-12 and CFC-113 are decreasing more slowly than anticipated ${ }^{8}$ along with the unexpected new production of several minor $\mathrm{CFCs}^{9-11}$, raising the spectre of illicit sources of these gases as well.

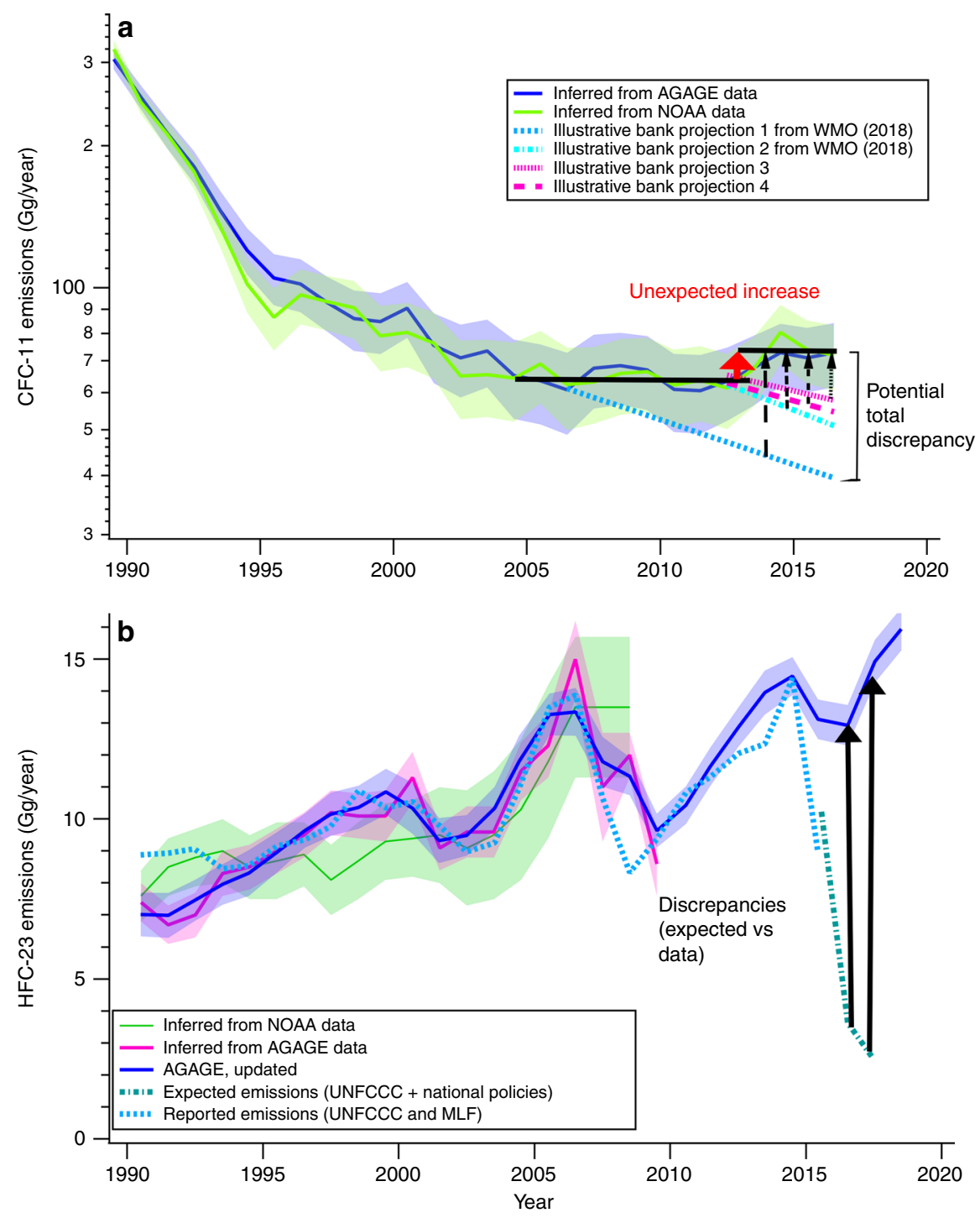

Fig. 1 Emissions of CFC-11 and HFC-23 since 1990. a CFC-11 emissions with estimated $1 \sigma$ error bars inferred from two different global data sets (set 1 (blue line) is from the AGAGE network, whereas set 2 (green) is from the NOAA network). Also shown are illustrative projections of emissions assuming no production outside of the Montreal Protocol and using different assumptions about bank sizes and release rates (blue and cyan lines from ref. ${ }^{21}$, which assumes about 4.3-4.9\% bank release rates/year, whereas pink lines include larger banks within the range of ref. ${ }^{8}$, adopting 3-3.5\%/year). Black horizontal lines depict averaged values for the data for 2004-2013 and for 2014-2016 as in ref. 4; the red arrow highlights the unexpected increase in emissions after 2013, indicating likely extra production. Black dotted and dash-dotted lines with arrows illustrate the dependence of the total discrepancy between inferred emissions from data vs. expected values from the illustrative banks. Adapted from Figs. 1-4 of ref. ${ }^{21}$. b HFC-23 emissions with estimated $1 \sigma$ error bars inferred from two different data sets (sets 2 (pink) and 3 (blue, updated from pink in ref. ${ }^{12}$ ) are from the AGAGE network, whereas set 1 (green) is from the NOAA network, along with emissions based on national reports to the UNFCCC and Montreal Protocol Multi-Lateral Fund (MLF) through 2015 (light blue dashed line), and emissions expected based on national reports to the UNFCCC plus national policies (teal green dash-dotted line) described in ref. ${ }^{12}$. Solid black lines with arrows highlight recent discrepancies between inferred emissions from data vs. expected values from international and national policies. Adapted from Figs. 2-7 of ref. ${ }^{21}$, updated using ref. ${ }^{12}$. 
Furthermore, there is the current situation of HFCs, which may undermine another great success story of the Protocol. HFCs were introduced into the economy mainly as non-ozonedepleting substitutes for CFCs, but are potent greenhouse gases. As emissions increased, governments pondered whether it was best to control them under the climate treaty, which was responsible for greenhouse gases, or under the Protocol, which was the catalyst for HFC use in the first place. The result was the Kigali Amendment of the Montreal Protocol agreed to in 2016, which levied much more stringent controls of HFCs than were possible under the current climate treaty ${ }^{1}$.

The story then takes another turn. HFC-23 emissions have increased more than expected in the last few years ${ }^{12}$, apparently falling between the cracks of successful pre-2015 actions using available technology under the climate treaty, and could undermine the formal 2020 start of Kigali (Fig. 1b) ${ }^{12}$. The discrepancy for 2017 is about $12 \mathrm{Gg} /$ year, or about $1.5 \mathrm{Gt} \mathrm{CO}_{2}$-eq if maintained for a decade (Fig. 1b). If HFC-23 emissions do not decline this year, Kigali's accomplishments will be called into question.

Leaking banks of ODSs. The Montreal Protocol aims to reduce emissions of CFCs and other ODSs indirectly by controlling their production and consumption. A major gap in this strategy is that substantial emissions leak from three major CFC 'banks'-old air conditioners, refrigerators and insulating foams. When summed, these leakages could delay the recovery of the ozone hole by as

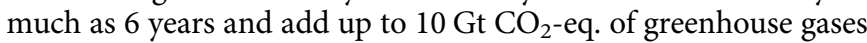
to the atmosphere (for comparison, the European Union has pledged in the Paris Agreement to reduce its greenhouse gas emissions by a total of $\sim 7 \mathrm{Gt}$ equivalent $\mathrm{CO}_{2}$ between 2019 and $2030)^{8}$. Recent studies have emphasized that we really do not have good estimates about the sizes of the remaining banks of chemicals, or how much they are leaking; this limits attempts to quantify the extent of illicit production (Fig. 1a) ${ }^{5,8}$.

Other emissions slipping through the treaty. The Montreal Protocol also does not consider ODSs used as feedstocks in making new chemicals or produced as co-products in industrial processes, as it was judged that such gases would be contained and destroyed in the manufacturing process. Neither of these judgements turned out to be correct for $\mathrm{CCl}_{4}$, whose production for direct uses was phased out in the Montreal Protocol but displays much larger inferred emissions than expected ${ }^{13}$. Recent studies indicate that carbon tetrachloride has fugitive emissions, e.g., when it is used as a feedstock to make certain HFCs and as a co-product from overchlorination in the production of cleaning agents and solvents including polychloroethylene and chloromethanes. These emissions add up to about $15 \mathrm{Gg} /$ year $^{14}$ or about $0.3 \mathrm{Gt} \mathrm{CO}_{2}$-eq/decade. Although the Protocol encourages Parties to find alternatives to these uses, it has held back in formalizing controls. Unexpectedly large emissions of CFC-113 and $113 \mathrm{a}$ of about $7 \mathrm{Gg} /$ year (about $0.4 \mathrm{Gt} \mathrm{CO}_{2}$-eq/decade) also likely stem from leakage of feedstocks and/or intermediates. These $\mathrm{CCl}_{4}$ and CFC-113 emissions are of the same order as the $15 \pm 5 \mathrm{Gg} /$ year increase observed for CFC-11 after 2012.

The question of $\mathrm{N}_{2} \mathrm{O}$. Nitrous oxide is now the most significant ozone-depleting emission to the atmosphere, as well as the third most important greenhouse gas in terms of radiative forcing ${ }^{15}$. Moreover, the global emissions of nitrous oxide are accelerating ${ }^{16}$. Unless nitrous oxide is mitigated, it will continue to deplete the upper atmosphere ozone and undermine the gains of the Montreal Protocol.

\section{The next steps}

The Protocol has been clearly effective in drawing down the largest culprits of ozone depletion, but now it is time to address the unfinished business.

Toughen compliance. The basic approach to compliance of the Montreal Protocol is that Parties are expected to 'self-report' their own non-compliance. This report is then taken up by the Protocol's Implementation Committee, which aims to find an 'amicable solution'. This has worked fairly well in reducing dramatically the large amounts of production occurring through the 70 s to 90 s, and this short-term success is rightly celebrated. However, recent findings about renewed or excessive emissions suggest that we are reaching the limits to this approach and it's time to consider using more stringent compliance measures contained in the Protocol.

Eliminate feedstocks and co-products. As noted above, emissions coming from chemicals used as feedstocks for producing other chemicals, or released as co-products of a production process, are not controlled under the Protocol. Technologies exist to combat this (e.g., by separating and burning off unwanted coproducts) ${ }^{14}$ and it is time now for Parties to negotiate stricter controls of these sources.

Stop the leakages. Leakages from CFC banks should be halted by including policies for their safe destruction into the Protocol. This should also cover the banks of the Halons (compounds containing bromine, once used mainly in fire extinguishers), which could be recovered and destroyed. There are already precedents in international law to control materials that threaten people and the environment, e.g., the Basel Convention on Hazardous Wastes.

Drawdown nitrous oxide. Governments have been unwilling to tackle $\mathrm{N}_{2} \mathrm{O}$, because two-thirds of its anthropogenic flux comes from agriculture and some believe that the cost of mitigating $\mathrm{N}_{2} \mathrm{O}$ will translate into higher food costs. However, there is also evidence that emissions can be cut cost-effectively through means such as boosting the nitrogen-use efficiency of crops, which itself will bring many added benefits ${ }^{17}$. Therefore, it is time to finally draw down these emissions and avoid their risk to the ozone layer and climate change.

Include environmental monitoring for effective implementation. Up to now, observational studies of ODSs and HFCs in the atmosphere have been conducted independently by the scientific community or by individual governments and have provided a critical but unofficial way to monitor progress of the Montreal Protocol. Now it is time to make these studies systematic by introducing regular environmental monitoring of CFCs, Halons, HCFCs, HFCs, $\mathrm{CCl}_{4}$, and $\mathrm{N}_{2} \mathrm{O}$ into the Protocol itself. These data are needed by the Parties to enable them to track progress and assure compliance. We note that many Multilaeral Environmental Agreements already include monitoring such as the International Convention on the Regulation of Whaling, the Convention on Long Range Transboundary Air Pollution, the Minamata Convention on Mercury, and the Stockholm Convention on Persistent Organic Pollutants ${ }^{18}$.

Protect climate by protecting the ozone layer. The IPCC ${ }^{19}$ recently articulated the serious consequences of exceeding a global average temperature increase of $1.5^{\circ} \mathrm{C}$ (we have already reached $0.9^{\circ} \mathrm{C}$ ), whereas studies point out that we are far off course in staying even below $2.0^{\circ} \mathrm{C}^{20}$. Hence, there is unprecedented urgency in reducing as quickly as possible not only the 
original gases targeted by the Protocol but also all ODSs and their substitutes that contribute to global warming. These include carbon tetrachloride, CFCs-11, 12, 113, 113a, 114, and 115, the Halons, the HCFCs, the HFCs, and $\mathrm{N}_{2} \mathrm{O}$. Indeed, even after the Kigali Amendment, the HFCs could still add over $20 \mathrm{Gt} \mathrm{CO}_{2}$ equivalent emissions to the atmosphere between 2020 and $2060^{21}$, suggesting the need for a 'Kigali-plus Amendment' to the Protocol, which would accelerate their planned drawdown.

Summing up, the Montreal Protocol has achieved remarkable success through its flexibility and adaptive responses to scientific and technological advances, and is hailed as the signature environmental success story of the twentieth century. It is time for it to adapt again if it is to be a twenty-first century success story.

Received: 16 June 2020; Accepted: 31 July 2020;

Published online: 26 August 2020

\section{References}

1. Birmpili, T. Montreal Protocol at 30: the governance structure, the evolution, and the Kigali Amendment. Comptes Rendus Geosci. 350, 425-431 (2018).

2. Velders, G., Anderson, S. O., Daniel, J. S., Fahey, D. W. \& McFarland, M. The importance of the Montreal Protocol in protecting climate. Proc. Natl Acad. Sci. USA 104, 4814-4819 (2007).

3. Heath, E. Amendment to the Montreal Protocol on substances that deplete the ozone layer (Kigali Amendment). Int. Leg. Mater. 56, 193-205 (2017).

4. Montzka, S. A. et al. An unexpected and persistent increase in global emissions of ozone-depleting CFC-11. Nature 557, 413 (2018).

5. UNEP. Decision XXX/3 TEAP Task Force Report on Unexpected Emissions of Trichlorofluoromethane (CFC-11) - Final Report (Volume 1). http://38.108.69. 235/meeting/oewg/oewg-41/presession/Background-Documents/TEAP_Task_ Force_Dec_XXX-3_on_Unexpected_CFC-11_Emissions_May_2019.pdf

6. Dhomse, S. S. et al. Delay in recovery of the Antarctic ozone hole from unexpected CFC-11 emissions. Nat. Commun. 10, 1-12 (2019).

7. Fleming, E. L., Newman, P. A., Liang, Q. \& Daniel, J. S. The impact of continuing CFC-11 emissions on stratospheric ozone. J. Geophys. Res., 125, e2019JD031849 (2020)

8. Lickley, M. et al. Quantifying contributions of chlorofluorocarbon banks to emissions and impacts on the ozone layer and climate. Nat. Commun. 11, 1-11 (2020).

9. Vollmer, M. K. et al. Atmospheric histories and emissions of chlorofluorocarbons CFC-13 $\left(\mathrm{CClF}_{3}\right), \mathrm{SCFC}-114\left(\mathrm{C}_{2} \mathrm{Cl}_{2} \mathrm{~F}_{4}\right)$, and CFC-115 $\left(\mathrm{C}_{2} \mathrm{ClF}_{5}\right)$. Atmos. Chem. Phys. 18, 979-1002 (2018)

10. Adcock, K. E. et al. Continued increase of $\mathrm{CFC}-113 \mathrm{a}\left(\mathrm{CCl}_{3} \mathrm{CF}_{3}\right)$ mixing ratios in the global atmosphere: emissions, occurrence and potential sources. Atmos. Chem. Phys. 18, 4737-4751 (2018).

11. Laube, J. C. et al. Newly detected ozone-depleting substances in the atmosphere. Nat. Geosci. 7, 266-269 (2014).

12. Stanley, K. M. et al. Increase in global emissions of HFC-23 despite near-total expected reductions. Nat. Commun. 11, 1-6 (2020)

13. Liang, Q., Newman, P. A. \& Reimann, S. SPARC Report on the Mystery of Carbon Tetrachloride, SPARC Report No. 7, WCRP-13/2016, https://doi.org/ 10.3929/ethz-a-010690647 (2016).
14. Sherry, D., McCulloch, A., Liang, Q., Reimann, S. \& Newman, P. A. Curren sources of carbon tetrachloride $\left(\mathrm{CCl}_{4}\right)$ in our atmosphere. Env. Res. Lett. 13, 024004 (2018)

15. Ravishankara, A. R., Daniel, J. S. \& Portmann, R. W. Nitrous oxide $\left(\mathrm{N}_{2} \mathrm{O}\right)$ : the dominant ozone-depleting substance emitted in the 21 st century. Science 326 123-125 (2009).

16. Thompson, R. L. et al. Acceleration of global $\mathrm{N}_{2} \mathrm{O}$ emissions seen from two decades of atmospheric inversion. Nat. Clim. Chang 9, 993-998 (2019).

17. UNEP 2013. Drawing down $\mathrm{N}_{2} \mathrm{O}$ to protect climate and the ozone layer. $A$ UNEP Synthesis Report (United Nations Environment Programme (UNEP), Nairobi, Kenya).

18. Ausubel, J. H. \& Victor, D. G. Verification of international environmental agreements. Ann. Rev. Energy Env. 17, 1-43 (1992).

19. Masson-Delmotte, V., et al. Global warming of 1.5 C. An IPCC Special Report on the Impacts of Global Warming (IPCC, 2018).

20. Höhne, N. et al. Emissions: world has four times the work or one-third of the time. Nature 579, 25-28 (2020).

21. WMO (World Meteorological Organization), Scientific Assessment of Ozone Depletion: 2018. Global Ozone Research and Monitoring Project-Report No. 58, p. 588 (World Meteorological Organization, Geneva, Switzerland, 2018).

\section{Acknowledgements}

S.S. acknowledges support by the VoLo foundation and by the Martin Chair in Environmental Studies at MIT. J.A. acknowledges support by Sussex Sustainability Research Programme, University of Sussex. A.R.R. acknowledges support by Colorado State University.

\section{Author contributions}

S.S., A.R.R., and J.A. designed the paper jointly and all contributed equally to writing the text. S.S. and A.R.R. designed the figure and S.S. prepared the figure.

\section{Competing interests}

The authors declare no competing interests.

\section{Additional information}

Correspondence and requests for materials should be addressed to S.S.

Reprints and permission information is available at http://www.nature.com/reprints

Publisher's note Springer Nature remains neutral with regard to jurisdictional claims in published maps and institutional affiliations.

\footnotetext{
Open Access This article is licensed under a Creative Commons Attribution 4.0 International License, which permits use, sharing, adaptation, distribution and reproduction in any medium or format, as long as you give appropriate credit to the original author(s) and the source, provide a link to the Creative Commons license, and indicate if changes were made. The images or other third party material in this article are included in the article's Creative Commons license, unless indicated otherwise in a credit line to the material. If material is not included in the article's Creative Commons license and your intended use is not permitted by statutory regulation or exceeds the permitted use, you will need to obtain permission directly from the copyright holder. To view a copy of this license, visit http://creativecommons.org/ licenses/by/4.0/.
}

(c) The Author(s) 2020 